\title{
Leachability of Self-Compacting Concrete (SCC) Incorporated With Fly Ash and Bottom Ash by Using Synthetic Precipitation Leaching Procedure (SPLP)
}

\author{
Aeslina Abdul Kadir ${ }^{1,}$, , Mohd Ikhmal Haqeem Hassan ${ }^{2, \text { b }}$ \\ ${ }^{1,2}$ Faculty of Civil and Environmental Engineering, \\ Universiti Tun Hussein Onn Malaysia (UTHM), \\ 86400 Parit Raja, Batu Pahat Johor, Malaysia
}

(Corresponding email: a aeslina@uthm.edu.my, ${ }^{b}$ mohd.ikhmal.haqeem@gmail.com )

Keywords: self compaction concrete; fly ash; bottom ash; waste products; leachability; heavy metals.

\begin{abstract}
Fly ash (FA) and bottom ash (BA) are some of waste generated by coal-fired power plants, which contains large quantities of toxic and heavy metals. The combustion of coal after been heated at specific temperatures and pressures in power stations produces ash. FA and BA must be properly managed and disposed without causing any harmful environmental effects. In recent years, many researchers have been interested to study on the properties of self-compacting concrete (SCC) incorporated with FA and BA but there was very limited research from the combination of FA and BA towards the environmental needs. Therefore, this study was focused in determining the leachability of heavy metals of SCC incorporated with FA and BA by using Synthetic Precipitation Leaching Procedure (SPLP). The samples were obtained from coal-fired power plant located at Kapar, Selangor. As such, the potential heavy metals leached out from SCC that is produced with FA as replacement for Ordinary Portland Cement (OPC) and BA as replacement for sand with the ratios from $10 \%$ to $30 \%$ respectively were designated and casted. There are eight heavy metals of concern such as $\mathrm{As}, \mathrm{Cr}, \mathrm{Pb}, \mathrm{Zn}, \mathrm{Cu}, \mathrm{Ni}, \mathrm{Mn}$ and $\mathrm{Fe}$. The results show that all heavy metals were leached below the permissible limits from USEPA and EPAV except for As which is the only heavy metal that leaches in large amount even in the control sample. This is probably due to the influence from the acidic extraction fluid, causing As to leach out in higher amounts during the extraction process. All in all, the uses FA and BA in SCC up to $20 \%$ seem to be an environmental friendly practice as far as leaching of heavy metals in the concrete is comply with the standard.
\end{abstract}

\section{Introduction}

Fly ash (FA) and bottom ash (BA) are some of waste materials in the coal-fired power plants that can potentially be used as coal combustion products. Generally, the size, shape and chemical composition determines their beneficial reuse as a component of building materials like cement, sand, or gravel. The uses of coal combustion products involve the substitution of these products to another product based on its performance criteria as mentioned by United States Environmental Protection Agency, USEPA [1]. The combustion of coal after being heated at specific temperatures and pressures in power stations produces ash. It also mentioned that from the burning process of coal, $80 \%$ of product will become fly ash and remain $20 \%$ of production is bottom ash $[2,18,19]$.

According to Department of Environment (DOE) Malaysia, the FA and BA are hazardous waste, namely any waste falling within the categories of waste listed in the first schedule of the Environment Quality (Scheduled Wastes) Regulations in 2005. The concentration of trace elements in ash is extremely variable and depends on the type and composition of the parent fuel, conditions during combustion and efficiency of emission control devices [3]. These wastes were either incinerated, treated physically and chemically, solidified or disposed off in securing landfill depending on their characteristics. In addition, FA and BA are some of the waste that was granted 
conditional approval to be managed under special management as stipulated under the same regulations that could be used as raw material for construction such as concrete production.

Apart from the potential usage of FA and BA, heavy metals such as arsenic, chromium, nickel and cadmium can be found in these waste materials [4]. Health concerns have been expressed regarding to the safe level of exposure of these material in building [5]. Little is known about the leachability of concrete structure made with fly ash and bottom ash. Hence, leaching tests using Synthetic Precipitation Leaching Procedure (SPLP) [6] was carried out to investigate the levels of possible leachates of the heavy metals from the manufactured concrete incorporated with combination of FA and BA. The information regarding chemical properties of concrete incorporating FA and BA is required to ensure it can be safely utilized in certain application.

\section{Experimental Programs}

Materials. Ordinary Portland Cement (OPC) was used. It was manufactured by Lafarge (Malaysia) which satisfied to BS EN 197-1: 2000 [7] and exceed the quality requirements specified in the Malaysian Standard MS 197-2: 2007 [8]. BA and FA were obtained from a coal fired power plant located at Peninsula, Malaysia. Aggregate and sand used in SCC manufacture generally complied with the requirements of EN 206-1 [12]. For aggregates, sizes from 14-20 mm were prepared by sieving method. In this research, X-ray fluorescence (XRF) technique was used to determine the heavy metals of various materials especially OPC, FA and BA. The materials were prepared as a pellet sample by using the Pressed Pellet Technique. The results were shown in Table 1.

Table 1: Heavy metals of FA, BA and OPC

\begin{tabular}{clccc} 
Heavy metals & Formula & \multicolumn{3}{c}{ Concentration (mg/L) } \\
& & $\boldsymbol{F A}$ & $\boldsymbol{B A}$ & $\boldsymbol{O P C}$ \\
Chromium & $\mathrm{Cr}$ & 228 & 176 & 54 \\
Manganese Oxide & $\mathrm{MnO}$ & 900 & 800 & 800 \\
\hline Iron (III) Oxide & $\mathrm{Fe}_{2} \mathrm{O}_{3}$ & 41600 & 52600 & 30200 \\
Nickel & $\mathrm{Ni}$ & 107 & 88 & 19 \\
Copper & $\mathrm{Cu}$ & 101 & 38 & 26 \\
Zinc & $\mathrm{Zn}$ & 52 & 31 & 164 \\
Arsenic & $\mathrm{As}$ & 38 & 12 & 37 \\
Lead & $\mathrm{Pb}$ & 62 & 18 & 60 \\
\hline
\end{tabular}

A total of 26 chemical compounds or elements were detected in FA, BA and OPC. By considering the constraint of laboratory apparatus, only selected parameter were considered to be tested by using Atomic Absorption Spectrometry (AAS). Henceforth, the analysis of the leachability of SCC incorporated with FA and BA is narrowed down to these few specific heavy metals. The heavy metals selected are $\mathrm{As}, \mathrm{Cr}, \mathrm{Pb}, \mathrm{Zn}, \mathrm{Cu}, \mathrm{Ni}, \mathrm{Mn}$ and $\mathrm{Fe}$.

Mix Proportions. The initial design of mix proportions of SCC incorporating with FA and BA were presented. There were ten mixed that has been casted including for control $(0 \%)$ and incorporating $10 \%, 20 \%, 30 \%$ of FA and BA. Total binder for all the samples were between $530 \mathrm{~kg} / \mathrm{m}^{3}$ to $550 \mathrm{~kg} / \mathrm{m}^{3}$ respectively. The samples were used $150 \mathrm{~mm}$ cubes.

Testing of the samples. Each mixed proportions were tested for their workability of SCC in order to classify it at SCC. These tests are the filling ability, passing ability and segregation resistance according to BS EN 12350-8, 12, 11 [9] respectively. Curing was then done in accordance to BS EN 12390-2 [10] and compressive strength at 28 days were determined from compression test in BS EN 12390-3 [11]. 
For leaching testing in this research, the Synthetic Precipitation Leaching Procedure (SPLP) [6] was used. SPLP is an agitated extraction that is used to provide information on the mobility (leachability) of organic and inorganic constituents from liquids, soils and wastes. The SPLP, which is described in USEPA Method 1312, calls for the use of one of two leaching fluids depending on the location of the sample site in the case of soil samples. For sites east of the Mississippi River, the leaching fluid is a solution of $60 \%$ of sulfuric acid and $40 \%$ of nitric acid in distilled water until the $\mathrm{pH} \mathrm{4.2.} \mathrm{For} \mathrm{sites} \mathrm{west} \mathrm{of} \mathrm{the} \mathrm{Mississippi} \mathrm{River,} \mathrm{a} \mathrm{solution} \mathrm{of} \mathrm{sulfuric} \mathrm{acid} \mathrm{and} \mathrm{nitric} \mathrm{acid} \mathrm{in} \mathrm{distilled}$ water, $\mathrm{pH}$ 5.0, is used as the leaching fluid. If the sample is a waste or wastewater, the extraction fluid employed is the $\mathrm{pH} 4.2$ solution. For this research, extraction fluids with $\mathrm{pH} 4.2$ solution were used. The size samples used was less than $9.5 \mathrm{~mm}$.

After the determination of the extraction fluid has been done, the samples were prepared in screw-capped polyethylene bottles which were filled with crushed concrete samples and leaching fluid at the ratio of 1:20.The bottles were agitated at $30 \mathrm{rpm}$ for 18 hours in an end-over-end manner. The leachate collected was then filtered using $0.7 \mu \mathrm{m}$ glass fiber filters, preserved the samples before being analyzed using AAS to determine the leaching metals.

\section{Result and Discussions}

Characteristics of the Materials. As recorded in Table 1, it shows that the major elements of these three samples are $\mathrm{Fe}_{2} \mathrm{O}_{3}$ with $41600 \mathrm{mg} / \mathrm{L}$ in FA, $52600 \mathrm{mg} / \mathrm{L}$ in BA and $30200 \mathrm{mg} / \mathrm{L}$ in OPC. The second highest elements in FA, BA and $\mathrm{OPC}$ are $\mathrm{TiO}_{2}$. It was recorded that the highest $\mathrm{TiO}_{2}$ was in FA sample with $15800 \mathrm{mg} / \mathrm{L}$ followed by BA with $10800 \mathrm{mg} / \mathrm{L}$ and $2000 \mathrm{mg} / \mathrm{L}$ for OPC. Other than that, Barium was also recorded higher in FA and BA with 2388 and $1340 \mathrm{mg} / \mathrm{L}$ respectively. Overall, it is seen that majority of the concentrations of elements in FA are much higher than that in BA, which OPC has small amounts only as compared to FA.

Leachability of Heavy metals. All the samples were analyzed using AAS to determine the leaching metals. The obtained data of leachate concentrations from procedure of SPLP are tabulated in Table 2.

Table 2: Result for heavy metals in SCC samples using SPLP

\begin{tabular}{|c|c|c|c|c|c|c|c|c|c|c|c|c|}
\hline \multirow[b]{2}{*}{$\begin{array}{l}\text { Heavy } \\
\text { metals }\end{array}$} & \multirow{2}{*}{ 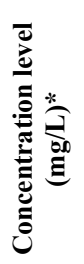 } & \multirow{2}{*}{ 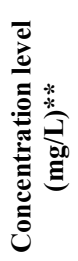 } & \multicolumn{10}{|c|}{ Specimens } \\
\hline & & & ن⿺辶大 & 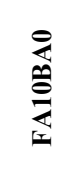 & 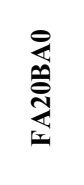 & 产 & 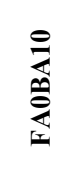 & 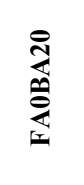 & 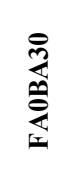 & 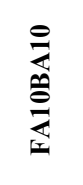 & 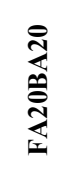 & 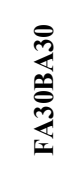 \\
\hline As & 5 & 2.8 & 9.54 & 8.669 & 5.487 & 3.894 & 9.945 & 7.923 & 9.074 & 7.677 & 5.778 & 6.968 \\
\hline $\mathrm{Cr}$ & 5 & 0.8 & 0.013 & - & - & - & - & - & - & - & - & - \\
\hline $\mathrm{Pb}$ & 5 & 4 & 0.266 & 0.324 & 0.355 & 0.436 & 0.566 & 0.627 & 0.667 & 0.711 & 0.719 & 0.746 \\
\hline $\mathrm{Zn}$ & 500 & 1200 & 0.111 & 0.126 & 0.142 & 0.123 & 0.149 & 0.16 & 0.14 & 0.167 & 0.18 & 0.161 \\
\hline $\mathrm{Cu}$ & 100 & 800 & 0.023 & 0.022 & 0.018 & 0.018 & 0.022 & 0.024 & 0.024 & 0.014 & 0.006 & 0.006 \\
\hline $\mathrm{Ni}$ & 1.34 & 88 & 0.009 & 0.023 & 0.015 & 0.134 & - & 0.082 & - & - & 0.093 & 0.015 \\
\hline $\mathrm{Fe}$ & - & - & - & - & - & - & - & - & - & - & - & - \\
\hline $\mathrm{Mn}$ & - & - & 0.058 & 0.279 & 0.179 & - & - & - & - & - & - & - \\
\hline
\end{tabular}

*USEPA (1996) [16]

** EPAV (2005) [17]

Table 2 summarized the AAS result for heavy metals using SPLP. Generally, the data displays that the concentrations of all the heavy metals in leachate from all the samples mixture were less than allowable concentration limits set by USEPA and EPAV except for As. It is the only heavy 
metal that leaches in large amounts even in the control sample. Some of the reason for the high amount of As leaching is explained whereby the metals leachate concentration is directly affected by the $\mathrm{pH}$ of the solution in Aubert et al., research [12]. Other researchers also mentioned that either Portland cement or FA contains a certain amount heavy metals and the leachability of some heavy metals is greatly dependent on the leachant [13].

The highest heavy metals recorded were As with $9.54 \mathrm{mg} / \mathrm{L}$. This level was slightly more than concentration level set by USEPA and EPAV. Not only that, all the samples were recorded higher in As with $9.945 \mathrm{mg} / \mathrm{L}$ from FA0BA10 and the samples that was closed but still above the concentration level from USEPA was FA20BA0 sample with $5.487 \mathrm{mg} / \mathrm{L}$. Similarly, incorporated $20 \%$ of FA and $20 \%$ BA recorded with $5.778 \mathrm{mg} / \mathrm{L}$ of As leaching. To be highlighted, the only sample that below the limit from USEPA was FA30BA0, with $3.894 \mathrm{mg} / \mathrm{L}$. SCC incorporated with FA and BA were recorded similar or below the control sample in term of leaching of As that may caused by the production of Portland cement itself. This stems from the known presence of most of the naturally occurring trace toxic metals in the raw materials used in the manufacture of cement [14].

Such low concentrations were recorded from all the specimens of $\mathrm{Zn}, \mathrm{Cu}, \mathrm{Ni}$ and $\mathrm{Mn}$. For $\mathrm{Zn}$, the control sample and incorporated with FA and BA samples were in range 0.111 to $0.18 \mathrm{mg} / \mathrm{L}$ that was extremely low from the concentration level. On the other hand, the $\mathrm{Cu}$ was also recorded below the limit with value as low as 0.006 from FA20BA20 and FA30BA30. It's proved that incorporated with FA and BA in SCC those not contributes the leaching of $\mathrm{Cu}$ at all. The similar behaviors are also reported from leaching of $\mathrm{Ni}$ from control specimen with $0.009 \mathrm{mg} / \mathrm{L}$ which the lowest value and some of the samples are not detected of Ni leaching such as for FA0BA10, FA0BA30, and FA10BA10 samples.

As for $\mathrm{Cr}$ and $\mathrm{Mn}$, only the control sample, FA10BA0 and FA20BA0 were detected also with low concentration and below the limit set by USEPA and EPAV. The undetectable concentrations of $\mathrm{Fe}, \mathrm{Cr}$ and $\mathrm{Mn}$ were due to insufficient concentrations in the raw materials and the ashes to overcome the high volatility of their compounds [15].

\section{Conclusions.}

Elemental composition and heavy metals of various materials especially OPC, FA and BA were determined by using XRF. Overall it was found that concentrations of elements in FA were generally higher compared to the concentration of elements from BA and OPC. There were 10 different mixed proportions including the control sample, samples incorporated $10 \%, 20 \%$ and $30 \%$ of FA or BA or both. As for environmental concerns, the leachability of SCC incorporated with FA and BA by using SPLP were the priority in this research. From the result, it shows that incorporated of FA and BA in SCC are potential able and these materials are safe to be implemented as a part of the building materials because it similarly to control sample and the heavy metals recorded was low and some of it was not detected except for As. As a conclusion, Specimen FA20BA20 was the potential sample to incorporated FA and BA into SCC as it displays the equality with both aspects; properties and environmental needs. 


\section{References.}

[1] J. van der Geer, J.A.J. Hanraads, R.A. Lupton, The art of writing a scientific article, J. Sci. Commun. 163 (2000) 51-59.

[2] Mohd Sani M. S. H., Muftah F., Muda Z., "The Properties of Special Concrete Using Washed Bottom Ash (WBA) as Partial Sand Replacement",International Journal of Sustainable Construction Engineering \& Technology Vol. 1, No 2, December 2010.

[4] Y. Wei, T. Shimaoka, A. Saffarzadeh, F. Takahashi, "Mineralogical characterization of municipal solid waste incineration bottom ash with an emphasis on heavy metal-bearing phases", Journal of Hazardous Materials, Volume 187, Issues 1-3, 15 March 2011, Pages534-543.

[5] X. G. Li, Y. Lv, B. G. Ma, Q. B. Chen, X. B. Yin, S. W. Jian., "Utilization of municipal solid waste incineration bottom ash in blended cement", Journal of Cleaner Production, Volume 32, September 2012, Pages 96-100.

[6] US Environmental Protection Agency (USEPA), Synthetic Precipitation Leaching Procedure (SPLP), Method 1312, September 1994.

[7] EN 197-1: 2000, "Cement - part 1: composition, specifications and conformity criteria for common cements," 2000.

[8] EN 206-1: 2000, "Concrete - part 1: specification, performance, production and conformity," 2000.

[9] BS EN 12350: 2010, “Testing fresh concrete - part 8, 11 and 12: self-compacting concrete" 2010.

[10] BS EN 12390-3: 2000, “Testing hardened concrete - part 2: making and curing specimens for strength tests," 2000.

[11] BS EN 12390-3: 2002, "Testing hardened concrete - part 3: compressive strength of test specimens," 2002.

[12] J. E. Aubert, B. Husson, and A. Vaquier, "Use of municipal solid waste incineration fly ash in concrete," Cement and Concrete Research, vol. 34, pp. 957-963, 2004.

[13] Y. Qijun, S. Nagataki, L Jinmei, T.Saeki, M. Hisada," The leachability of heavy metals in hardened flyash cement and cement solidified fly ash", 2005.

[14] S.R. Hiller, C.M.Sangha, B.A Plunkett, P.J Walden," Long term leaching of toxic metals from Portland cement concrete", 1999.

[15] Zhu W., Bartos P.J.M, "Permeation properties of self-compacting concrete". Cement and Concrete Research, Vol. 33, 2003, pp. 921-926.

[16] USEPA, Hazardous Waste Characteristics Scoping Study, US Environmental Protection Agency, Office of Solid Waste, 1996.

[17] EPAV, Guidelines for Hazard Classification of Solid Prescribed Industrial Waste, Publication 996, June, 2005.

[18] Kadir A. A., Hassan M. I. H., "An Overview of Fly Ash and Bottom Ash Replacement in Self Compaction Concrete” Key Engineering Materials Vols. 594-595 pp 465-470, 2014.

[19] Siddique R., Paratibha Aggarwal, Yogesh Aggarwal, "Influence of water/powder ratio on strength properties of self-compacting concrete containing coal fly ash and bottom ash", Construction and Building Materials 29 73-81, 2012. 